\title{
Vision-Related Quality of Life and Subscale Items Following Intravitreal Ranibizumab Injections for Central Retinal Vein Occlusion
}

Fumiki Okamoto ( $\square$ fumiki-o@md.tsukuba.ac.jp )

University of Tsukuba

Tomoya Murakami

University of Tsukuba

Yoshimi Sugiura

University of Tsukuba

Shohei Morikawa

University of Tsukuba

Takahiro Hiraoka

University of Tsukuba

Tetsuro Oshika

University of Tsukuba

\section{Research Article}

Keywords: vision-related quality of life (VR-QOL), intravitreal ranibizumab injections, VFQ-25, CRVO

Posted Date: July 20th, 2021

DOI: https://doi.org/10.21203/rs.3.rs-724586/v1

License: (9) (i) This work is licensed under a Creative Commons Attribution 4.0 International License. Read Full License 


\section{Abstract}

The aim of this study was to evaluate the vision-related quality of life (VR-QOL) before and after intravitreal ranibizumab injections (IVR) for central retinal vein occlusion (CRVO) and investigate subscale items of VR-QOL in detail. This multicenter, open-label, prospective study included 23 patients with treatment naïve CRVO and 22 age-matched normal controls. VR-QOL was assessed by the 25 -Item Visual Function Questionnaire (VFQ-25) before and up to 12 months post-treatment. The VFQ-25 composite score and 12 subscales were compared between groups. The VFQ-25 composite scores in CRVO showed significant improvement throughout the treatment period compared with those at the baseline. The VFQ-25 composite score before and after treatment in CRVO was significantly lower than that in normal controls. The subscale items, including general health, general vision, near activities, social functioning, mental health, role difficulties, dependency, and peripheral vision, in CRVO were significantly lower than those in the normal controls even after treatment. Vision-related QOL was low in patients with CRVO before treatment and improved with IVR. Even after treatment, the values of several subscale items were lower than those in normal controls. Patients with CRVO require treatment aimed at further improving visual function as well as social and psychological care.

\section{Introduction}

Central retinal vein occlusion (CRVO) causes a significant loss of vision in the elderly, ${ }^{1}$ yet only limited treatments are available for this condition. ${ }^{2}$ Since the introduction of anti-vascular endothelial growth factor (VEGF) therapy, ${ }^{3,4}$ the visual prognosis of patients with CRVO has improved, although, many patients still complain of visual impairment after anti-VEGF treatment. Poor baseline visual acuity, ${ }^{5}$ poor visual acuity after the initial injection, ${ }^{6}$ coexistence of internal carotid artery disease, and diabetic retinopathy ${ }^{5}$ are the factors that exacerbate visual outcomes in patients with CRVO who have undergone anti-VEGF treatment. Retinal microstructure-investigated using optical coherence tomography (OCT)central retinal thickness and ellipsoid zone status at baseline, ${ }^{7-9}$ disorganization of inner retinal layers, ${ }^{9}$ and inner retinal layer reflectivity ${ }^{10}$ are reported to be related to the visual prognosis of CRVO. Although the goal of the treatment of CRVO is to improve the quality of vision-including visual acuity-the ultimate aim is to improve the quality of life (QOL) of patients with CRVO.

Traditional measures of clinical outcomes, such as visual acuity, are increasingly being complemented by assessments of visual function of patients and perceived QOL. The National Eye Institute 25-Item Visual Function Questionnaire (VFQ-25) is a vision-related quality of life (VR-QOL) instrument designed to assess patients' perception of their visual function and QOL. ${ }^{11}$ VFQ-25 has been used to track outcomes of several retinal diseases, such as epiretinal membrane (ERM), ${ }^{12,13}$ macular hole $(\mathrm{MH}),{ }^{14}$ retinal detachment (RD), ${ }^{15-17}$ proliferative diabetic retinopathy (PDR), ${ }^{18,19}$ diabetic macular edema (DME) ${ }^{19}$ and branch retinal vein occlusion (BRVO). ${ }^{20,21}$ 
Deramo et al. assessed the VR-QOL of patients with CRVO using the VFQ-25 and found that their VR-QOL was lower than that of normal controls and was associated with visual acuity in the better-seeing eye and the number of systemic medical conditions. ${ }^{22}$ The CRUISE study ${ }^{3}$ and the GALILEO/ COPERNICUS study ${ }^{4,23}$ used the VFQ-25 to assess VR-QOL of patients with CRVO and observed improvement in VRQOL after treatment. However, there are no reports on the relationship between VR-QOL and visual function in patients with CRVO, or a detailed evaluation of changes in subscale after treatment. The purpose of the present study was to evaluate VR-QOL before and after treatment for CRVO in comparison with that of normal controls and investigate the subscale of VR-QOL in detail.

\section{Results}

We included 23 patients with CRVO and 22 normal controls. Clinical characteristics of patients with CRVO and normal controls are mentioned in Table 1. No difference was observed between the two groups in terms of age or sex. The VFQ-25 composite score of patients with CRVO was significantly worse than that of normal controls. All patients with CRVO continued with the study treatment. The mean number of injections during the treatment period was $5.6 \pm 2.0$ (range 3-8 injections). None of the patients experienced ocular treatment-emergent serious adverse events, such as retinal detachment, endophthalmitis, vitreous hemorrhage, iris neovascularization, and glaucoma. During the follow-up period, none of the patients underwent cataract surgery (in the affected eye or the fellow eye).

Table 1

Clinical characteristics of patients with central retinal vein occlusion (CRVO) and normal controls at baseline

\begin{tabular}{|llll|}
\hline & CRVO & Normal controls & P values \\
\hline Age (years) & $72.2 \pm 11.1$ & $65.8 \pm 10.4$ & $\mathrm{P}=0.07$ \\
\hline Sex (men/women) & $13 / 10$ & $10 / 12$ & $\mathrm{P}=0.66$ \\
\hline BCVA of CRVO eye (logMAR) & $0.79 \pm 0.56$ & $-0.06 \pm 0.07$ & $\mathrm{P}<0.001$ * \\
\hline BCVA of fellow eye (logMAR) & $0.01 \pm 0.13$ & $-0.07 \pm 0.06$ & $\mathrm{P}<0.001$ * \\
\hline Central foveal thickness ( $\mu$ m) & $770 \pm 319$ & - & - \\
\hline VFQ-25 composite score (point) & $62.6 \pm 16.9$ & $89.4 \pm 7.4$ & $\mathrm{P}<0.001$ * \\
\hline Duration of disease (month) & $2.1 \pm 2.5$ & - & - \\
\hline Values are presented as the mean \pm standard deviation. & & \\
\hline $\begin{array}{l}\text { BCVA: best-corrected visual acuity, logMAR: logarithm of the minimum angle of resolution, VFQ-25: } \\
\text { the 25-Item National Eye Institute Visual Function Questionnaire. }\end{array}$ & \\
\hline * Significantly different from the normal controls (Mann-Whitney U test) & \\
\hline
\end{tabular}

\section{Functional and anatomical outcomes}


Figure 1 shows changes from baseline best-corrected visual acuity (BCVA) and central foveal thickness (CFT). A significant improvement was observed in BCVA and CFT after 1 month of treatment.

\section{Changes in VR-QOL in patients with CRVO}

The VFQ-25 composite score improved significantly at all observation periods compared with the baseline score ( $\mathrm{P}<0.005$ in all) (Fig. 2). The VFQ-25 composite scores in patients with CRVO at baseline and 3,6 , and 12 months after treatment were $62.6 \pm 16.9,70.6 \pm 15.6,72.2 \pm 15.8$, and $74.3 \pm 14.6$, respectively, and the mean increase from baseline VFQ-25 composite score was 8.0 points at 3 months, 9.6 points at 6 months, and 11.7 points at 12 months (Fig. 2).

\section{VFQ-25 composite score and subscales in patients with CRVO and controls}

Table 2 shows the VFQ-25 composite scores and 12 subscales in normal controls and patients with CRVO before and after treatment. The average VFQ-25 composite score in normal controls was $89.4 \pm 7.4$, and VFQ-25 composite scores in patients with CRVO before and after treatment were worse than that of normal controls ( $P<0.001$ in both cases). The intravitreal ranibizumab (IVR) treatment for 12 months significantly improved the subscale of general vision, ocular pain, near activities, distance activities, mental health, role difficulties, dependency, and composite score. Several subscale items, including general health, general vision, near activities, social functioning, mental health, role difficulties, dependency, and peripheral vision in patients with CRVO, were significantly lower than those in the normal controls even after treatment. 
Table 2

The National Eye Institute 25-Item Visual Function Questionnaire (VFQ-25) composite score and 12 subscales of normal controls and patients with CRVO before and after intravitreal ranibizumab treatment

\begin{tabular}{|c|c|c|c|c|c|c|}
\hline \multirow{2}{*}{$\begin{array}{l}\text { VFQ-25 } \\
\text { Questionnaire } \\
\text { scale }\end{array}$} & \multirow{2}{*}{$\begin{array}{l}\text { Normal } \\
\text { controls }\end{array}$} & \multicolumn{5}{|c|}{ Patients with CRVO } \\
\hline & & Baseline & $\begin{array}{l}\text { P-value } \\
\text { compared with } \\
\text { normal } \\
\text { controls }\end{array}$ & $\begin{array}{l}\text { Post- } \\
\text { treatment } \\
\text { at } 12 \\
\text { months }\end{array}$ & $\begin{array}{l}\text { P-value } \\
\text { compared } \\
\text { with } \\
\text { baseline } \\
\text { value }\end{array}$ & $\begin{array}{l}\text { P-value } \\
\text { compared } \\
\text { with normal } \\
\text { controls }\end{array}$ \\
\hline $\begin{array}{l}\text { General } \\
\text { health }\end{array}$ & $\begin{array}{l}64.8 \\
(16.7)\end{array}$ & $\begin{array}{l}43.2 \\
(11.4)\end{array}$ & $<0.001^{\star}$ & $\begin{array}{l}50.0 \\
(17.2)\end{array}$ & 0.206 & $0.027^{\star}$ \\
\hline $\begin{array}{l}\text { General } \\
\text { vision }\end{array}$ & $\begin{array}{l}78.2 \\
(10.5)\end{array}$ & $\begin{array}{l}46.4 \\
(17.9)\end{array}$ & $<0.001^{*}$ & $\begin{array}{l}60.0 \\
(16.8)\end{array}$ & $0.013^{+}$ & $<0.001^{*}$ \\
\hline Ocular pain & $\begin{array}{l}86.9 \\
(13.1)\end{array}$ & $\begin{array}{l}72.2 \\
(22.8)\end{array}$ & $0.029 *$ & $\begin{array}{l}84.7 \\
(17.4)\end{array}$ & $0.008^{\dagger}$ & 1.000 \\
\hline $\begin{array}{l}\text { Near } \\
\text { activities }\end{array}$ & $\begin{array}{l}85.6 \\
(12.4)\end{array}$ & $\begin{array}{l}47.6 \\
(26.4)\end{array}$ & $<0.001^{\star}$ & $\begin{array}{l}63.0 \\
(22.9)\end{array}$ & $0.033^{+}$ & $<0.001^{*}$ \\
\hline $\begin{array}{l}\text { Distance } \\
\text { activities }\end{array}$ & $\begin{array}{l}86.0 \\
(13.0)\end{array}$ & $\begin{array}{l}63.5 \\
(21.5)\end{array}$ & $<0.001^{\star}$ & $\begin{array}{l}75.5 \\
(16.5)\end{array}$ & $0.036^{+}$ & 0.062 \\
\hline $\begin{array}{l}\text { Social } \\
\text { functioning }\end{array}$ & $\begin{array}{l}94.0 \\
(8.9)\end{array}$ & $\begin{array}{l}72.6 \\
(17.1)\end{array}$ & $<0.001^{*}$ & $\begin{array}{l}79.9 \\
(13.7)\end{array}$ & 0.133 & $0.002^{\star}$ \\
\hline Mental health & $95.5(7.3)$ & $\begin{array}{l}52.8 \\
(21.8)\end{array}$ & $<0.001^{*}$ & $\begin{array}{l}67.7 \\
(19.3)\end{array}$ & $0.004^{\dagger}$ & $<0.001^{*}$ \\
\hline $\begin{array}{l}\text { Role } \\
\text { difficulties }\end{array}$ & $\begin{array}{l}91.5 \\
(10.5)\end{array}$ & $\begin{array}{l}62.5 \\
(22.8)\end{array}$ & $<0.001^{*}$ & $\begin{array}{l}79.2 \\
(19.2)\end{array}$ & $0.004^{\dagger}$ & $0.048^{*}$ \\
\hline Dependency & $\begin{array}{l}98.5 \\
(4.2)\end{array}$ & $\begin{array}{l}68.6 \\
(20.2)\end{array}$ & $<0.001^{*}$ & $\begin{array}{l}82.4 \\
(16.9)\end{array}$ & $0.004^{\dagger}$ & $0.002^{*}$ \\
\hline Driving & $\begin{array}{l}85.6 \\
(12.3)\end{array}$ & $\begin{array}{l}61.5 \\
(27.2)\end{array}$ & $0.013^{*}$ & $\begin{array}{l}73.1 \\
(25.8)\end{array}$ & 0.057 & 0.137 \\
\hline Color vision & $\begin{array}{l}94.3 \\
(10.7)\end{array}$ & $\begin{array}{l}83.8 \\
(14.7)\end{array}$ & $0.013^{\star}$ & $\begin{array}{l}85.9 \\
(12.8)\end{array}$ & 0.414 & 0.084 \\
\hline $\begin{array}{l}\text { Peripheral } \\
\text { vision }\end{array}$ & $\begin{array}{l}87.5 \\
(18.5)\end{array}$ & $\begin{array}{l}65 \\
(20.5)\end{array}$ & $<0.001^{*}$ & $\begin{array}{l}69.4 \\
(20.2)\end{array}$ & 0.257 & $0.008^{*}$ \\
\hline $\begin{array}{l}\text { Composite } \\
\text { score }\end{array}$ & $\begin{array}{l}89.4 \\
(7.4)\end{array}$ & $\begin{array}{l}62.6 \\
(16.9)\end{array}$ & $<0.001^{\star}$ & $\begin{array}{l}73.9 \\
(14.7)\end{array}$ & $0.002^{\dagger}$ & $<0.001^{*}$ \\
\hline \multicolumn{7}{|c|}{ Mean (standard deviation) } \\
\hline * Significantly & ferent $\mathrm{fr}$ & he norn & ntrols (Mann- & tney U tes & & \\
\hline
\end{tabular}




\section{Relationship between VR-QOL and visual acuity in patients with CRVO}

Table 3 shows the relationship between the VFQ-25 composite score and 12 subscales and BCVA in patients with CRVO before and after treatment. At baseline, the VFQ-25 composite score and all subscales were not significantly associated with BCVA. The VFQ-25 composite score and subscale items social functioning and dependency showed a significant correlation with BCVA 12 months after treatment.

Table 3

The relationship between the National Eye Institute 25-Item Visual Function Questionnaire (VFQ-25) composite score and 12 subscales, and visual acuity in patients with CRVO before and after intravitreal ranibizumab treatment

\begin{tabular}{|lllll|}
\hline $\begin{array}{l}\text { VFQ-25 Questionnaire } \\
\text { scale }\end{array}$ & \multicolumn{2}{l}{$\begin{array}{l}\text { VFQ-25 vs. BCVA at } \\
\text { baseline }\end{array}$} & \multicolumn{2}{l|}{$\begin{array}{l}\text { VFQ-25 vs. BCVA at 12-month post- } \\
\text { treatment }\end{array}$} \\
\cline { 2 - 5 } & $\mathbf{r}$ & $\mathbf{P}$ & $\mathbf{r}$ & $\mathbf{P}$ \\
\hline General health & 0.243 & 0.276 & -0.136 & 0.603 \\
\hline General vision & 0.018 & 0.938 & -0.425 & 0.089 \\
\hline Ocular pain & -0.102 & 0.652 & -0.050 & 0.850 \\
\hline Near activities & -0.140 & 0.545 & -0.340 & 0.182 \\
\hline Distance activities & -0.230 & 0.317 & -0.409 & 0.103 \\
\hline Social functioning & -0.026 & 0.912 & -0.577 & 0.015 * \\
\hline Mental health & 0.036 & 0.873 & -0.424 & 0.090 \\
\hline Role difficulties & -0.207 & 0.356 & -0.453 & 0.068 \\
\hline Dependency & -0.389 & 0.073 & -0.543 & 0.024 * \\
\hline Driving & -0.061 & 0.829 & -0.440 & 0.176 \\
\hline Color vision & -0.427 & 0.060 & -0.389 & 0.152 \\
\hline Peripheral vision & -0.363 & 0.115 & -0.330 & 0.196 \\
\hline Composite score & -0.184 & 0.412 & -0.554 & 0.021 * \\
\hline BCVA: best-corrected visual acuity & & & \\
\hline * Significantly correlation between two parameters (Spearman rank correlation test) \\
\hline
\end{tabular}

\section{Discussion}


The VFQ-25 composite score improved from 62.6 points before treatment to 74.3 points 12 months after treatment in this study. The VFQ-25 composite score in CRVO at baseline was 66.9 points in a study by Deramo et al. $^{22}$ and 77.4 points in the COPERNICUS study, ${ }^{23}$ and the scores observed in our study were lower than those of the COPERNICUS study. Eligible patients had BCVA of 20/40 to 20/320 in the COPERNICUS study, ${ }^{23}$ whereas there was no criterion for BCVA of eligible patients in the present study, consequently, the range of BCVA was from 20/20 to 20/2000. In the present study, the VFQ-25 composite score at baseline may have been lower than that in the COPERNICUS study because our study included patients with extremely poor vision.

The mean increase from baseline VFQ-25 composite score was 9.5 points after 6 months, and 11.7 points after 12 months of treatment in this study. The mean increase from the baseline VFQ-25

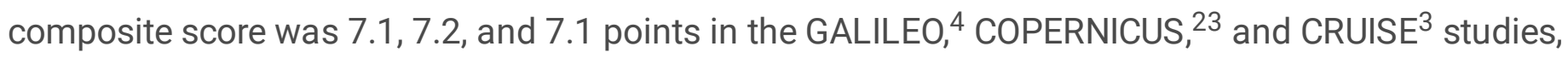
respectively, after 6 months and 7.8, 7.5, and 7.1 points respectively, after 12 months of treatment. In our study, the mean number of injections for 12 months was 5.6, which was lower than the 9.8 in the CRUISE study, ${ }^{3}$ and 11.8 in the GALILEO study. ${ }^{4}$ Despite these results, there was a greater improvement in the VFQ-25 composite score in the present study than in other studies, suggesting that pro re nata $(3+\mathrm{PRN})$ is acceptable as a standard treatment for CRVO in terms of QOL.

The VR-QOL has been investigated in patients with various retinal diseases, including $E R M,{ }^{12,13} \mathrm{MH}^{14}$ RD, ${ }^{15-17} \mathrm{PDR}^{18,19}{ }^{10 M E}{ }^{19}$ and BRVO. ${ }^{20,21}$ The mean increase from baseline VFQ-25 composite score was 11.7 points in $E R M,{ }^{13} 6.9$ points in $\mathrm{MH}^{14}{ }^{14} 10.8$ points in $\mathrm{PDR}^{19} 6.0$ points in $\mathrm{DME},{ }^{19}$ and $9.0-9.4$ points in BRVO. ${ }^{21,24}$ Despite differences in the observation period and inclusion criteria, the improvement in the VFQ-25 composite score of patients with CRVO was nearly similar to that of patients with other retinal diseases after treatment, suggesting that anti-VEGF treatment in patients with CRVO has clinical significance.

The IVR treatment for CRVO improved BCVA and CFT immediately after treatment and was maintained throughout the following 12 months. In the present study, the improvement in BCVA at 12 months was 0.2 logarithm of the minimum angle of resolution (logMAR) (10 letters). In the CRUISE ${ }^{3}$ and GALILEO study, ${ }^{4}$ BCVA at 12 months after anti-VEGF treatment was 13.9 and 16.9 letters from baseline, respectively. The reason for the less extent of improvement in BCVA in our study compared with that in other studies may be the inclusion criteria. As mentioned earlier, patients with CRVO in the CRUISE and GALILEO studies had a BCVA of 20/40 to 20/320,3,4 whereas, in the present study, the range of BCVA of the patients at baseline was 20/20 to 20/2000. The improvement in BCVA was lower than that in the abovementioned studies because our study included patients with extremely poor vision and patients with good vision.

We observed that the baseline VFQ-25 composite score was not associated with BCVA, whereas the posttreatment composite score showed a significant correlation with post-treatment BCVA. Consistently, Deramo VA et al. also reported that the VR-QOL of pre-treatment patients with CRVO was not associated with visual acuity. ${ }^{22}$ Visual acuity and VR-QOL are related in common eye diseases ${ }^{25}$; however, the 
relationship between VR-QOL and visual functions (except visual acuity) has been indicated in many retinal diseases. The VR-QOL in $\mathrm{ERM}^{17,23}$ and $\mathrm{MH}^{21}$ was associated with metamorphopsia and not visual acuity. In PDR, ${ }^{22,23} \mathrm{DME},{ }^{23}$ after $\mathrm{RD},{ }^{18}$ and vitreous floaters, ${ }^{26}$ contrast sensitivity affected the VR-QOL. Moreover, stereopsis was associated with VR-QOL after RD surgery. ${ }^{20}$ Visual dysfunctions such as metamorphopsia ${ }^{27}$ and aniseikonia ${ }^{28}$ have been reported in patients with CRVO; hence, visual function factors other than visual acuity may be involved in the deterioration of VR-QOL.

In the present study, IVR treatment for patients with CRVO significantly improved subscale items of general vision, ocular pain, near activities, distance activities, mental health, role difficulties, and dependency. At baseline, all subscale items were lower in patients with CRVO than in normal controls. Even after treatment, subscale items, including general health, general vision, near activities, social functioning, mental health, role difficulties, dependency, and peripheral vision in CRVO, were significantly lower than those in the normal controls. In addition, the VFQ-25 composite score and subscale items social functioning, and dependency after treatment showed a significant correlation with BCVA. Most subscale items in pre-treatment in patients with CRVO were lower than those in normal controls, consistent with the findings of previous reports. ${ }^{22}$ Although anti-VEGF treatment for CRVO improved the values of many subscale items, those related to the quality of vision (general vision, near activities, and peripheral vision) and psychosocial functioning (social functioning, mental health, role difficulties, and dependency) were more impaired than those in normal controls even after treatment. Further treatment aimed at improving visual function, as well as social and psychological care by medical social workers, are necessary.

The limitations of this study were a small sample size and short follow-up duration. We evaluated the patients for 12 months after treatment. In the COPERNICUS study, BCVA in patients with CRVO treated with intravitreal aflibercept injection at 24 months was 3.2 letters less than that at 12 months. ${ }^{29}$ As CRVO is a retinal disease with a poor prognosis, it is important to monitor visual functions and QOL in the long term. Future studies with a larger sample size and longer follow-up duration will further improve our understanding of VR-QOL in patients with CRVO.

\section{Methods}

\section{Study design}

This was a multicenter, open-label, prospective study and was conducted in accordance with the Declaration of Helsinki. Institutional Review Board (IRB)/Ethics Committee approval was obtained from the University of Tsukuba Hospital and Mito Kyodo General Hospital. Before inclusion, all patients and normal subjects were informed of the nature of the study, and their informed consent was obtained. Treatment naïve patients with CRVO referred to the Tsukuba University Hospital or Mito Kyodo General Hospital were enrolled in this study. Patient inclusion criteria were, center-involving macular edema secondary to CRVO; CFT > $250 \mu \mathrm{m}$; age, 18 years or more and less than 85 years; and patient with paper- 
based informed consent. The exclusion criteria were, previous history of vitreoretinal surgery; previous history of ophthalmic disorders except mild refractive errors and mild cataract; within 90 days of macular edema treatment involving sub-Tenon triamcinolone acetonide, intravitreal bevacizumab, IVR, intravitreal aflibercept, topical steroid, carbonic anhydrase inhibitors; within 90 days of intraocular surgery; the contralateral eye of CRVO; poor control of hypertension and diabetic mellitus; within 30 days of laser treatment. We also included age-matched normal controls in this study.

\section{Study visits and assessments}

BCVA and retinal microstructure were assessed monthly from pre-treatment up to 12 months posttreatment. VR-QOL was examined pre-treatment and at 3,6, and 12 months post-treatment. BCVA measured on the Landolt chart was converted to the logMAR and used for subsequent analysis. The retinal microstructure was assessed using spectral-domain OCT (Cirrus high-definition OCT; Carl Zeiss, Dublin, CA, USA). Five-line Raster Cross scans were performed using the Cirrus analysis software version 3.0., and scans with a signal strength of more than $6 / 10$ were considered appropriate. The CFT was evaluated based on the obtained OCT images.

The VFQ-25 was used to examine VR-QOL in patients with CRVO. The VFQ-25 consists of 25 items that enable patients to assess visual symptoms and difficulties in daily activities. The answers to each of the 25 questions were sorted into 12 subscales, including general health, general vision, ocular pain, near activities, distance activities, social functioning, mental health, role difficulties, dependency, driving, color vision, and peripheral vision. The subscales were scored on a scale of 0-100 points, with 100 indicating the highest possible function or the least subjective impairment. We calculated the VFQ-25 composite score as the mean of the scores for the 11 subscales and excluded the general health subscale. The VFQ25 used in this study was the Japanese version, which was modified to fit Japanese culture and lifestyle. The modified NEI VFQ-25 questionnaire has been assessed for reliability and validity and is proven to accurately measure VR-QOL in the Japanese population. ${ }^{30}$

\section{Intraocular injections}

We treated the patients using three consecutive monthly IVR ( $0.5 \mathrm{mg}$, Lucentis; Genetech), followed by 3 + PRN. After three injections, the subjects were evaluated monthly and treated with intravitreal injections on PRN basis according to the protocol retreatment criteria. Re-administration criteria for PRN were as follows: CFT as assessed by OCT of $\geq 300 \mu \mathrm{m}$ in the study eye, new cystoid retinal changes, retinal bleeding or subretinal fluid on OCT, logMAR visual acuity decrease of $>0.1$ compared with values measured on the last visit.

\section{Statistical analysis}

The mean values and standard deviations were calculated. A Mann-Whitney $U$ test was performed to compare age, BCVA, and VR-QOL scores of patients with CRVO and normal controls. The chi-square test was used to check for sex differences between patients with CRVO and normal controls. A Wilcoxon signed-rank test was used to investigate changes in BCVA, CFT, and VFQ-25 composite scores. 
Associations between VFQ-25 composite scores and 12 subscales and BCVA at baseline and 12 months post-treatment were examined by the Spearman rank correlation test. All analyses were conducted using SPSS (version 27, IBC Corp., Chicago, IL, USA). A P-value $<0.05$ was considered statistically significant.

\section{Declarations}

Acknowledgements: None

Financial Support: This study was supported by Novartis Pharma K.K., Tokyo, Japan. No additional external funding was received for this study. The sponsor had no role in the design or conduct of this research.

Competing Interests: This study was supported by Novartis Pharma K.K., Tokyo, Japan. No additional external funding was received for this study. The sponsor had no role in the design or conduct of this research.

\section{Author contributions:}

Fumiki Okamoto and Tetsuro Oshika conduct this study.

Fumiki Okamoto wrote the main manuscript text.

Shohei Morikawa, Yoshimi Sugiura, and Tomoya Murakami had data collection.

Takahiro Hiraoka had data analysis.

All authors reviewed the manuscript.

\section{References}

1. Klein, R. et al. The relationship of age-related maculopathy, cataract, and glaucoma to visual acuity. Invest. Ophthalmol. Vis. Sci. 36, 182-191 (1995).

2. Mohamed, Q., McIntosh, R. L., Saw, S. M. \& Wong, T. Y. Interventions for central retinal vein occlusion: an evidence-based systematic review. Ophthalmology 114, 507-519, 524 (2007).

3. Campochiaro, P. A. et al. Sustained benefits from ranibizumab for macular edema following central retinal vein occlusion: twelve-month outcomes of a phase III study. Ophthalmology 118, 2041-2049 (2011).

4. Korobelnik, J. F. et al. Intravitreal aflibercept injection for macular edema resulting from central retinal vein occlusion: One-year results of the Phase 3 GALILEO study. Ophthalmology 121, 202-208 (2014).

5. Nagasato, D. et al. Factors associated with extremely poor visual outcomes in patients with central retinal vein occlusion. Sci. Rep. 10, 19667; 10.1038/s41598-020-76840-6 (2020). 
6. Etheridge, T. et al. Spectral domain optical coherence tomography predictors of visual acuity in the study of COmparative treatments for REtinal vein Occlusion 2 (SCORE2). Ophthalmol. Retina S2468$6530(20) 30503-0 ; 10.1016 / j$.oret.2020.12.016 (2020). Online ahead of print.

7. Tang, F. et al. Optical coherence tomography predictors of short-term visual acuity in eyes with macular edema secondary to retinal vein occlusion treated with intravitreal conbercept. Retina 40, 773-785 (2020).

8. Ciulla, T. A., Kapik, B., Grewal, D. S. \& Ip, M. S. Visual acuity in retinal vein occlusion, diabetic, and uveitic macular edema: central subfield thickness and ellipsoid zone analysis. Ophthalmol. Retina 5, 633-647 (2021).

9. Chan, E. W. et al. Disorganization of retinal inner layers and ellipsoid zone disruption predict visual outcomes in central retinal vein occlusion. Ophthalmol. Retina 3, 83-92 (2019).

10. Greenlee, T. E. et al. Inner retinal layer reflectivity as predictor of retinal vein occlusion visual acuity outcomes. Ophthalmol. Retina 4, 343-344 (2020).

11. Mangione, C. M. et al. Development of the 25 -item National Eye Institute Visual Function Questionnaire. Arch. Ophthalmol. 119, 1050-1058 (2001).

12. Khanna, R. I. et al. Monocular and binocular visual parameters associated to vision-related quality of life in patients with epiretinal membrane: a prospective cohort. Graefes Arch. Clin. Exp. Ophthalmol.; 10.1007/s00417-020-05064-1 (2021). Online ahead of print.

13. Okamoto, F., Okamoto, Y., Hiraoka, T. \& Oshika, T. Effect of vitrectomy for epiretinal membrane on visual function and vision-related quality of life. Am. J. Ophthalmol. 147, 869-874, 874.e1 (2009).

14. Fukuda, S. et al. Vision-related quality of life and visual function in patients undergoing vitrectomy, gas tamponade and cataract surgery for macular hole. Br. J. Ophthalmol. 93, 1595-1599 (2009).

15. Okamoto, F., Okamoto, Y., Hiraoka, T. \& Oshika, T. Vision-related quality of life and visual function after retinal detachment surgery. Am. J. Ophthalmol. 146, 85-90 (2008).

16. Ng, H., Vermeer, K. A., van Meurs, J. C. \& La Heij, E. C. Visual acuity inadequately reflects visionrelated quality of life in patients after macula-off retinal detachment surgery. Invest. Ophthalmol. Vis. Sci. 61, 34; 10.1167/iovs.61.10.34 (2020).

17. Potic, J. et al. Application of modified NEI VFQ-25 after retinal detachment to vision-related quality of life. Retina 41, 653-660 (2021).

18. Okamoto, F. et al. Vision-related quality of life and visual function following vitrectomy for proliferative diabetic retinopathy. Am. J. Ophthalmol. 145, 1031-1036 (2008).

19. Okamoto, F. et al. Vision-related quality of life and visual function after vitrectomy for various vitreoretinal disorders. Invest. Ophthalmol. Vis. Sci. 51, 744-751 (2010).

20. Campochiaro, P. A. et al. Ranibizumab for macular edema following branch retinal vein occlusion: Six-month primary end point results of a phase III study. Ophthalmology 117, 1102-1112.e1 (2010).

21. Clark, W. L. et al. Intravitreal aflibercept for macular edema following branch retinal vein occlusion: 52-week results of the VIBRANT study. Ophthalmology 123, 330-336 (2016). 
22. Deramo, V. A. et al. Vision-related quality of life in people with central retinal vein occlusion using the 25-item National Eye Institute Visual Function Questionnaire. Arch. Ophthalmol. 121, 1297-1302 (2003).

23. Brown, D. M. et al. Intravitreal aflibercept injection for macular edema secondary to central retinal vein occlusion: 1-Year results from the phase 3 COPERNICUS study. Am. J. Ophthalmol. 155, 429437.e7 (2013).

24. Brown, D. M. et al. Sustained benefits from ranibizumab for macular edema following branch retinal vein occlusion: 12-Month outcomes of a phase III study. Ophthalmology 118, 1594-1602 (2011).

25. Ishii, K., Kabata, T. \& Oshika, T. The impact of cataract surgery on cognitive impairment and depressive mental status in elderly patients. Am. J. Ophthalmol. 146, 404-409 (2008).

26. Mamou, J. et al. Ultrasound-based quantification of vitreous floaters correlates with contrast sensitivity and quality of life. Invest. Ophthalmol. Vis. Sci. 56, 1611-1617 (2015).

27. Manabe, K. et al. Metamorphopsia associated with central retinal vein occlusion. PLoS One 12, e0186737 (2017).

28. Okamoto, F. et al. Aniseikonia in various retinal disorders. Graefes Arch. Clin. Exp. Ophthalmol. 255, 1063-1071 (2017).

29. Heier, J. S. et al. Intravitreal aflibercept injection for macular edema due to central retinal vein occlusion: two-year results from the COPERNICUS study. Ophthalmology 121, 1414-1420.e1 (2014).

30. Suzukamo, Y. et al. Psychometric properties of the 25-item National Eye Institute Visual Function Questionnaire (NEI VFQ-25), Japanese version. Health Qual. Life Outcomes. 3, 65 (2005).

\section{Figures}




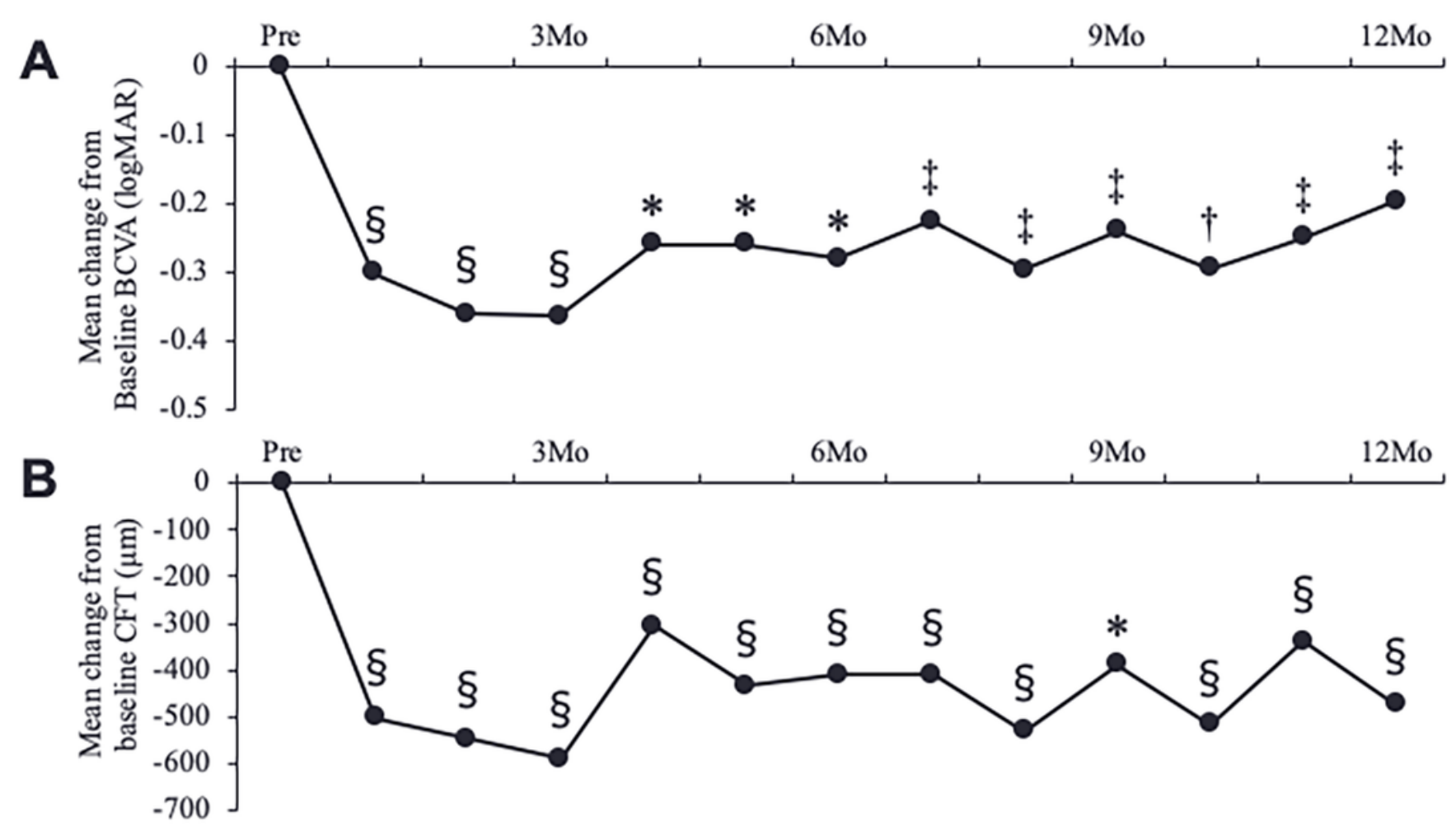

Figure 1

Mean change from baseline BCVA (a) and CFT (b) in patients with central retinal vein occlusion. $\S \mathrm{P}<$ 0.001 , ${ }^{\star} \mathrm{P}<0.005, \mathrm{TP}<0.01$, $¥ \mathrm{P}<0.05$ compared to baseline. BCVA: best-corrected visual acuity, CFT: central foveal thickness, Mo: months. 


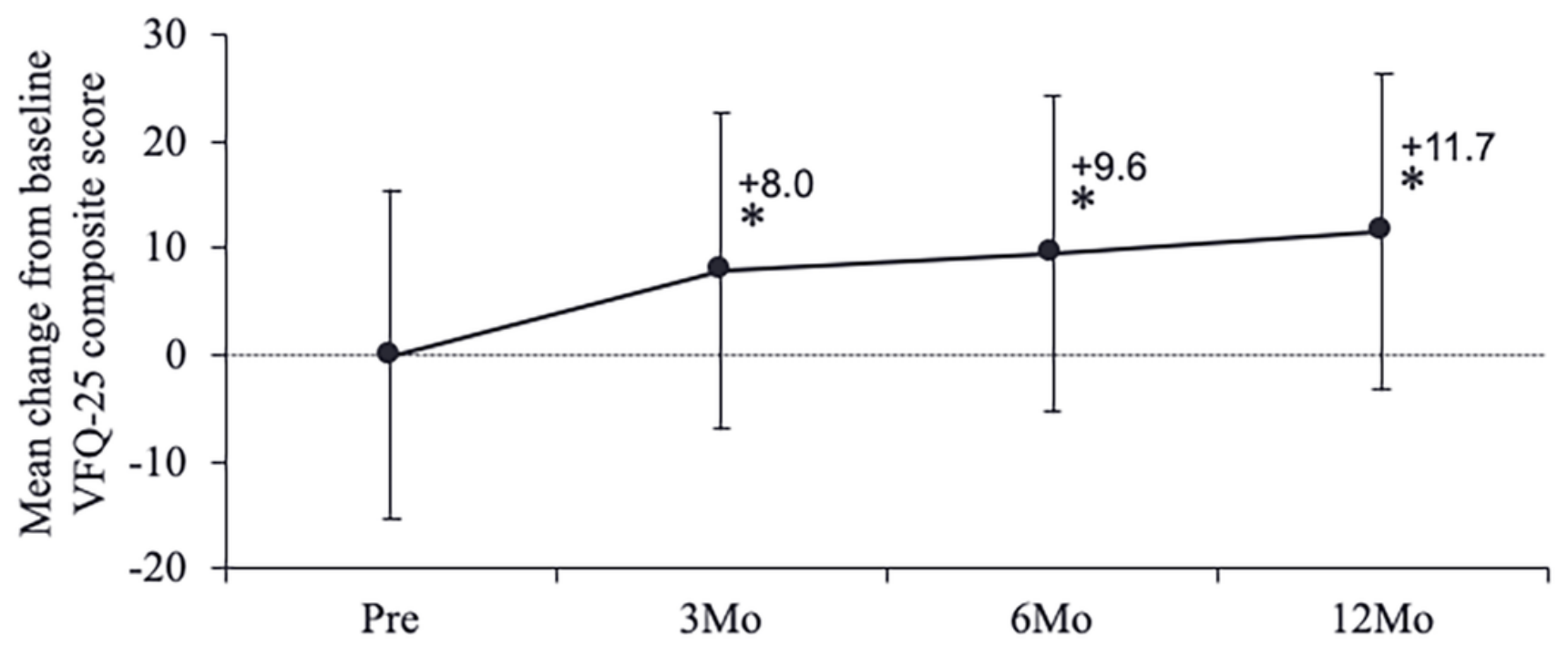

Figure 2

Mean change from the baseline VFQ-25 composite score in patients with central retinal vein occlusion. *P $<0.005$ compared to baseline. Error bars indicate standard deviations. VFQ-25: the 25-Item National Eye Institute Visual Function Questionnaire, Mo: months. 